\title{
TENDENCY TO BRUXISM IN PHYSIOTHERAPY TEACHERS AND CONSEQUENCES IN THE QUALITY OF LIFE
}

\author{
Joelma Magalhães da Costa'; Aline de Carvalho Santos²; Renata Bezerra Braga3; Tairine Correa de Melo3; \\ Raisa Seabra Carvalho ${ }^{4,5}$; Joanne Figueiredo De Oliveira ${ }^{4}$
}

\begin{abstract}
Introduction: Bruxism is characterized by the parafunctional act of tightening or grinding the teeth, which may occur in a conscious or unconscious way, during sleep or in wakefulness. It has become a growing concern in recent years due to its negative impact on quality of life (QOL) and also because it is considered an important risk factor for temporomandibular disorders. Objective: This study aimed to evaluate the QOL related to bruxism in physiotherapy teachers from a private institution through a questionnaire and their perception for such parafunction. Method: A cross-sectional, quantitative and exploratory study. The self-perception of bruxism was assessed through three questions from the Fonseca Anamnestic Indexand the perspective of QLV through the Quality of Life Questionnaire (SF-36), with a sample of 38 teachers of both genders. Results: Based on the results found, the level of statistical significance was set at $p<0,05$ for all tests. Among the 38 interviewees, $47,4 \%(n=18)$ of professionals were observed with bruxism, with a higher prevalence in the female gender. Regarding the comparisons of QOL in relation to bruxism, a statistically significant difference was found in relation to the dimension of Pain $(p=0,014)$, in which the mean for the bruxism group was $(59,8)$ and without bruxism $(78,5)$. Conclusion: There is a relation of the bruxism with the quality of life of the interviewees, and this habit mainly interferes in the domain of pain. Another aspect that was shown to be significantly associated with bruxism was nervous tension, in which the tense and nervous professionals were associated with self-perception of bruxism.
\end{abstract}

Keywords: Bruxism; Teachers; Quality of life.

\section{INTRODUCTION}

Bruxism is a parafunction characterized by the non-functional contact of the teeth, which can occur in a conscious or unconscious way, manifesting itself by the teeth tightening or grinding. For a correct diagnosis of such parafunction, it is necessary, besides the use of questionnaires, to carry out a clinical evaluation of the occlusion and dentition, musculature, habits of life and quality of sleep. It is not a disease, but when exacerbated it can lead to a pathophysiological disequilibrium of the stomatognathic system. ${ }^{(1)}$

Bruxism without an apparent cause is called the primary, while the secondary one is that associated with the use of psychoactive substances, drugs and medical disorders. (2) Some studies on the etiology of bruxism are still inconclusive. The current focus is on the fact that bruxism is part of an awakening reaction. This parafunctional activity seems to be modulated by several neurotransmitters of the Central Nervous System, but it cannot be said that it has an only central

regulation. Thus, bruxism may be associated with mandibular cranial dysfunctions, including headache, temporomandibular dysfunction (TMD), muscle pain, early loss of teeth due to excessive attrition and mobility, and interruption of sleep of the individual. ${ }^{(3,4)}$

The teacher falls into a professional category that lives under continuous tension and stress, because in addition to their usual responsibilities, the high competitiveness requires him facing new challenges and constant learning. In addition, the excess of teaching activities, interpersonal conflicts, number of students, work environment, among other factors, can also lead teachers to a state of tension and stress. ${ }^{(5)}$ According to research conducted by Gasparini et al. ${ }^{(6)}$ whose aim was to describe the teachers' health profile, it was concluded that teachers have more risk of psychological distress and more prevalence of minor psychological disorders, when compared to other groups such as doctors, merchants, engineers, etc.

Corresponding author: Name: Joelma Magalhães da Costa Address: Avenida General Rodrigo Otávio, 770 - Crespo, Força Aérea Brasileira, Hospital da Aeronáutica de Manaus - HAMN. Manaus - AM (Brazil). Cep: 69073177. E-mail: joelma.magalhaes@yahoo.com.br Telephone: +55 (92) 98137-5066

${ }^{1}$ Força Aérea Brasileira, Manaus (AM), Brazil.

Full list of author information is available at the end of the article.

Financial support: Own support.

Submission date 17 September 2016; Acceptance date 3 October 2016; Publication online date 15 December 2016 
Teaching is one of the professional categories that have most required changes due to the intensification of work pace. Traditionally, these professionals were assigned the role of teaching subjects, having gradually assumed functions, such as building health habits, psychological counseling, traffic education, among others. From this situation emerges a scenario with adverse effects, giving teachers a set of discomforts, in many cases destabilizing the psychosomatic economy and generating various diseases, which strongly influence the quality of life of these professionals. ${ }^{(7)}$

Currently, one of the main concerns of the academic community is the quality of working life (QWL) teachers. ${ }^{(8)}$ According to the World Health Organization ${ }^{(9)}$, Quality of life is the individual's perception of their position in life in the context of the culture and value system, in which they live in, as well as their goals, expectations, standards, and concerns. The work environment and psychosocial factors have been considered largely responsible for the health problems observed in teachers. ${ }^{(10)}$

In view of this, the present study aimed to verify the quality of life related to bruxism in physiotherapy teachers of a private institution through a questionnaire and their perception for such parafunction.

\section{METHOD}

The study in question is cross-sectional, quantitative and exploratory nature, which previously stipulated questionnaires were applied. All the volunteers validated their participation in the research by signing the Term of Free and Informed Consent (TFIC). The research was initiated after analysis and approval of the Research Ethics Committee (REC) according to protocol n. 0 1267414, CAAE: 44978015.9.0000.0010.

The evaluations were carried out with 38 teachers of the Physiotherapy course in a private institution of Manaus - AM, from the 1st to the 10th period, who were present in the classroom at the time of the approach, of both genders, with ages between 20 and 55 years. Teachers who did not attend a physiotherapy course, with an age group outside the stipulated one, and who were not in agreement with the TFIC and methodology were excluded.

The objectives of the research and the methodology were clarified to the participants in the classroom. The individuals of the research underwent an initial interview that consisted in obtaining information on the following aspects: age, gender, working time in the institution and hours worked. For the evaluation of the quality of life, each interviewee answered the Brazilian version of the Quality of Life Questionnaire - SF36, which is a questionnaire with eleven questions in relation to the individual perception of health, comparing their current health status to the previous year, as well as possible difficulties in performing activities of daily living, and whether this difficulty is related to their physical health, the degree of body pain in the last days and the interference of this in their daily activities. The sum of the points obtained corresponds for each volunteer a variable from 0 (zero) to 100 (one hundred), where 0 is worse, and 100 is the best score, determining its degree of quality of life. ${ }^{(11)}$

It was used to evaluate the tendency to the bruxism and nervous tension of the teachers, three questions of the Fonseca Anamnesis Index - FAl (Have you ever noticed if you have a habit like squeezing or grinding your teeth? Do you feel that your teeth do not articulate well? Do you consider yourself a tense/nervous person?), In which it is composed of 10 questions regarding parafunctional habits, presence of TMJ pain, migraine, bruxism and other aspects. Fisher's exact test was used to evaluate possible associations between categorical variables. In the comparisons of the continuous variables between two independent groups were used Student's t-test and the Mann Whitney U. E test and in comparison between three or more independent groups was used Kruskal-Wallys - Post HpocDunn test.

The database was processed using the Excel ${ }^{\circledR}$ software to Windows ${ }^{\circledR}$ and the statistical analyzes were done with the SPSS ${ }^{\circledR}$ (StatisticPackage for the Social Sciences, Chicago, IL, USA) software version 2.0 to Windows ${ }^{\circledR}$. The level of statistical significance was established in $p<0.05$ for all the tests.

\section{RESULTS}

We interviewed 38 professionals, with the mean age of $33.1( \pm 5.9)$ years and with greater occurrence of female gender $(65.8 \%)$.

The median working time was 12.5 months, with $75 \%$ of the sample presenting up to 35 months of work. As for working time (weekly), the average was $31.2( \pm 9.4)$ hours. Execution of work outside the university was confirmed by $60.5 \%(n=23)$ of the professionals, and on this group, $82.6 \%(n=19)$ reported working in one more location and $17.4 \%(n=4)$ confirmed work on two or more locations. As for those who showed tendency to bruxism $52.6(n=20)$ reported not to present and $47.4(n=18)$ reported a tendency to bruxism. The variables also verified the nervous tension which $31.6 \%$ ( $n=12$ ) did not report being tense and nervous people and $68.4(n=26)$ reported to be tense and nervous people.

When the variables that characterize the sample were compared to bruxism, the only significant difference was in charge of the nervous tension $(p=0.010)$ in which the characterized professionals by the presence of the nervous tension were associated with the tendency to bruxism, $88.9 \%$ $(n=16)$, whereas, in the groups with bruxism tendency, the association occurred with the absence of nervous tension, $50.0 \%(n=10)$. Regarding the comparisons of gender, age, working time, hours of work, others works, and extra hours in relation to the tendency to bruxism, the differences observed between the groups with and without tendency to bruxism were not representative in this sample (Table 1). 
Regarding to the comparison of the quality of life and the tendency to bruxism was detected a statistically significant difference in relation to the dimension of Pain $(p=0.014)$, so that the mean was higher in the group with no tendency

Table 1. Absolute and relative distribution for gender, work outside university, and nervous tension; And mean, standard deviation and median for age, time and hours of work and extra hours, according to bruxism.

\begin{tabular}{|c|c|c|c|c|c|}
\hline \multirow{3}{*}{ Variables } & \multicolumn{5}{|c|}{ Bruxism ** } \\
\hline & \multicolumn{2}{|c|}{ No $(n=20)$} & \multicolumn{2}{|c|}{ Yes $(n=18)$} & \multirow{2}{*}{$\mathbf{p}$} \\
\hline & $\mathbf{n}$ & $\%$ & $\mathbf{N}$ & $\%$ & \\
\hline Gender & & & & & $0.914 \S$ \\
\hline Female & 13 & 65.0 & 12 & 66.7 & \\
\hline Male & 7 & 35.0 & 6 & 33.3 & \\
\hline \multicolumn{6}{|l|}{ Age } \\
\hline Mean \pm deviation (Median) & \multicolumn{2}{|c|}{$33.9 \pm 5.3(34.5)$} & \multicolumn{2}{|c|}{$32.2 \pm 6.7(30.5)$} & 0.3787 \\
\hline \multicolumn{6}{|l|}{ Time of work (months) } \\
\hline Mean \pm deviation (Median) & \multicolumn{2}{|c|}{$23.1 \pm 27.6(' 1.0)$} & \multicolumn{2}{|c|}{$32.3 \pm 32.3(21.5)$} & $0.351 \mp$ \\
\hline \multicolumn{6}{|l|}{ Hours of work (weekly) } \\
\hline Mean \pm deviation (Median) & \multicolumn{2}{|c|}{$29.9 \pm 8.2(27.0)$} & \multicolumn{2}{|c|}{$32.6 \pm 10.6(30.0)$} & $0.371 \mp$ \\
\hline \multicolumn{3}{|l|}{$\begin{array}{l}\text { Work outside the } \\
\text { University }\end{array}$} & & & $0.483 \S$ \\
\hline No & 9 & 45.0 & 6 & 33.3 & \\
\hline Yes & 11 & 55.0 & 12 & 66.7 & \\
\hline \multicolumn{6}{|l|}{ Extra hours } \\
\hline Mean \pm deviation (Median) & \multicolumn{2}{|c|}{$21.9 \pm 7.9(20.0)$} & \multicolumn{2}{|c|}{$16.9 \pm 7.7(19.0)$} & $0.139 \mp$ \\
\hline Nervous Tension & & & & & 0.0109 \\
\hline Not tense/nervous person & 10 & 50.0 & 2 & 11.1 & \\
\hline Tense/nervous person & 10 & 50.0 & 16 & 88.9 & \\
\hline
\end{tabular}

ף: Fisher's exact test; §: Pearson's Chi-square test with continuity correction; ₹: Student t-test for independent groups; $₹$ : Mann Whitney U test;

** Percentages obtained on the total of each category of bruxism. to bruxism $(78.5 \pm 19.4)$ when compared to the group with tendency to bruxism $(59.8 \pm 24.9)$, remembering that the lower is the score, the worse is the quality of life. On the other dimensions, as well as on the general score, the observed differences were not representative among groups with and without tendency to bruxism (Table 2).

\section{DISCUSSION}

The research (12) about "Quality of life of teachers from Community Higher Education Institutions of Rio Grande do Sul", Found that $67 \%$ of the interviewees are female, while the rest (33\%) are male. This author's placement is in line with the studies of Rocha and Fernandes ${ }^{(8)}$, in which 91 of the teachers interviewed, 87 (95.60\%) were female and 04 (4.40\%) were male. From the presented discourses, it is evident that the data found in relation to the gender of the teachers interviewed were similar to the data presented in this study.

The study of Araújo et al, ${ }^{(13)}$ conducted in private schools of Salvador education, found that most teachers focused their activities in more than one private school (43.1\%), 20.2\% of the teachers worked in another public school and $27.7 \%$ of them had another paid activity in addition to the teaching activity. Thus confirming the results found in this study that $60.5 \%$ of the professionals accused of having jobs outside the university and, among this group, $82.6 \%$ reported working in more than one location and $17.4 \%$ reported working in two or more locations. From the analysis of this core of thought, we can see from the results of the research in question that this situation points to the fact that a significant number of teachers have to share their time in more than one field of work.

In accordance with Kuroiwaet $a l^{(11)}$ in QOL research using SF-36, evaluated 91 patients, $80.22 \%$ of them were female with TMJ, and found better values in domains of functional capacity (73.2), physical aspects (57.6) and social aspects (63.6), consistent with the domains of higher perception in

Table 2. Mean, standard deviation and median for the general quality of life scores and the SF-36 domains, according to bruxism.

\begin{tabular}{|c|c|c|c|c|c|c|c|}
\hline \multirow{3}{*}{$\begin{array}{c}\text { Quality of Life } \\
\text { SF- } 36\end{array}$} & \multicolumn{7}{|c|}{ Bruxism } \\
\hline & \multicolumn{3}{|c|}{ No $(n=20)$} & \multicolumn{3}{|c|}{ Yes $(n=18)$} & \multirow[b]{2}{*}{ pף } \\
\hline & Mean $\mp$ & $\begin{array}{l}\text { Standard } \\
\text { Deviation }\end{array}$ & Median $尹$ & Mean $\mp$ & $\begin{array}{l}\text { Standard } \\
\text { Deviation }\end{array}$ & Median $尹$ & \\
\hline Functional capacity & 89.0 & 9.8 & 92.5 & 86.9 & 15.9 & 95.0 & 0.631 \\
\hline Physical aspects & 73.8 & 37.6 & 100.0 & 77.8 & 29.6 & 87.5 & 0.718 \\
\hline PAIN & 78.5 & 19.4 & 79.0 & 59.8 & 24.9 & 66.5 & 0.014 \\
\hline General Health Status & 66.6 & 14.1 & 67.0 & 62.2 & 16.4 & 62.0 & 0.382 \\
\hline Vitality & 67.3 & 12.9 & 67.5 & 64.4 & 18.0 & 70.0 & 0.581 \\
\hline Social aspects & 78.3 & 19.0 & 75.0 & 77.3 & 21.5 & 81.5 & 0.883 \\
\hline Emotional aspects & 75.0 & 35.7 & 100.0 & 75.9 & 39.3 & 100.0 & 0.939 \\
\hline Mental health & 76.0 & 13.9 & 80.0 & 73.3 & 15.4 & 72.0 & 0.578 \\
\hline Quality of Life & 75.5 & 14.8 & 80.2 & 72.2 & 16.2 & 78.2 & 0.513 \\
\hline
\end{tabular}

₹: Student t-test for independent groups; ๆ: Fisher's exact test; ₹: Mann Whitney U test. 
this study. Confirming that the Pain and Functional Capacity aspects will interfere with the general state of health.

In the study of Contreras, ${ }^{(14)}$ in which conducted a research of 231 patients composed of 140 females and 91 males, a higher prevalence of bruxism in females was found, in agreement with the data found in this study, which 18 interviewees presented bruxism and among these 12 were female. According to Montero, ${ }^{(15)}$ the fact of having found two times more the presence of bruxism in females can be related to greater sensitivity to the psychological factors that trigger bruxism, in addition to being more aware of the problems related to health, since they made self-report about this problem.

Regarding the comparisons of gender, age, working time, hours worked, work outside the university and extra hours in relation to bruxism, the differences between the groups with and without bruxism were not representative in this sample, except in the nervous tension. From the 18 who presented bruxism, 16 were tense and nervous, and of the 20 who did not present bruxism, only 10 were tense and nervous.

In the study of Souza, ${ }^{(16)}$ performed with university professors in the biological area, to identify the QOL level of those individuals who were enrolled in post-graduation, there was a low level of stress management (12\%). Similar results were found by Troman e Woods, ${ }^{(17)}$ on the teaching career of teachers in the United Kingdom, where there is a trend of abandonment of the teaching profession caused by stress. Just like Vandera, ${ }^{(18)}$ affirms in a study that there is a correlation between emotional stress and bruxism. In the research of Martins, ${ }^{(19)}$ the majority of respondents who presented a severe degree of dysfunction and bruxism, considered themselves nervous or tense. Similarly, Leung et al, ${ }^{(20)}$ investigated the level of association between job satisfaction and the psychological effect of university teachers, identifying that six of the 26 items analyzed were related to teacher stress, in which the main factor was teacher recognition (37.5\%). The evidence found in this study also showed a very relevant level when compared to teachers with and without tendency to bruxism, in which of the 18 people who had a tendency to bruxism, 16 presented themselves as tense and nervous people. However, the prevalence of negative behaviors reported in stress management is worrying.

With regard to the quality of life and the tendency to bruxism, in the research of Carvalho ${ }^{(21)}$ held with police without being significant the profession of them, was evaluated the prevalence of bruxism in 394 selected police and just $64.6 \%$ were aware of the presence of this parafunction. The presence of emotional stress was registered in $45.69 \%$ of them, and between stressed police almost half of them $(48.3 \%)$ related teeth grinding during sleep and / or awake, lying significant association $(P=0.0004)$ between the presence of emotional stress and bruxism.
In this study, the domains in relation to pain were observed for those who presented tendency to bruxism with average of 59.8, general state of health of 62.2 and vitality of 64.4 . Therefore, there is a similarity between the worst domain, which is still pain and this is the lowest of all scores, thus showing a level of significance $p<0.014$; but it was observed another domain that is included the general state of health and vitality, in which also presented a low score. Those who did not present a tendency to bruxism did not have a higher score in all aspects in relation to those who presented tendency to bruxism.

\section{CONCLUSIONS}

The evidence suggests that those who present bruxism perception alter the quality of life of teachers and this parafunction mainly interferes in the domains of pain, general health and vitality, and when it is present in individuals shows a much lower quality of life than individuals who do not have it.

Another aspect that was significantly associated with bruxism was the nervous tension, which the professionals characterized by tension or nervousness were shown to be associated with the tendency to the parafunctional habit. Noting that quality of life may be affected in individuals with bruxism and this prevalence of negative behaviors reported in stress management is worrying both for the individual and for society.

Thus, it is proposed that this community in question seeks a better knowledge of the disorder that may be affecting them, and also the professionals to know preventive measures or even possible treatments. Few studies are carried out with this population, and further studies are needed, so they can deepen results and considerations on this subject.

\section{AUTHOR'S CONTRIBUTION}

ADCS, TCDM, RBB: Project; RS, JF: Methodological Design (planning of methods to generate results); ADCS, TCDM, RBB: Data Collection and Article Search; JMDC, RS, JF: Guidance and Development; JMDC: Writing and Critical Review of the Manuscript before final submission. All authors approved the final version of the manuscript.

\section{CONFLICTS OF INTEREST}

The author(s) declare that they have no competing interests.

\section{AUTHOR DETAILS}

${ }^{2}$ IAPES, Manaus (AM), Brazil.

${ }^{3}$ Centro Universitário do Norte (Uninorte), Manaus (AM), Brazil.

${ }^{4}$ Centro Universitário do Norte (Uninorte), Manaus (AM), Brazil.

${ }^{5}$ Centro Educacional Literatus, Manaus (AM), Brazil.

\section{REFERENCES}

1 Machado E, Machado P, Cunali PA, Dal Fabbro C. Sleep bruxism: Therapeutic possibilities based in evidences. Dental Press J Orthod. 2011; 16:58-64. 
2 American Academy of Sleep Medicine. International classification of sleep disorders, pocket version: diagnostic and coding manual. 2 nd ed. Westchester: American Academy of Sleep Medicine; 2006.

3 Kato T, Thie NMR, Huynh N, Miyawaki S, Lavigne GJ. Topical review: sleep bruxism and the role of peripheral sensory influences. J Orofac Pain. 2003; 17(3): 191-213.

4 Lobbezoo F, Zaag JVD, Naeije M. Bruxism: its multiple causes and its effectson dental implants - an update dreview. J Oral Rehabil. 2006 Apr; 33(4): 293-300.

5 Tavarez RRDJ, Braga PLA, Maia FEM, Malheiros AS. Temporomandibular disorder and severity in university professors. Revista Dor. 2013; 14(3): 187-191.

6 Gasparini SM, Barreto SM, Assunção AA. The Teacher, Working Conditions And The Effects On Your Health. Educ Pesqui. 2005; 31(2): 189-99.

7 Rocha VM, Fernandes MH. Quality of life elementary school teachers: a perspective for health promotion of worker. J Bras. Psiquiatr. 2008; 57(1): 23-27.

8 Lemos CAF, Nascimento JV, Borgatto AF. Parâmetros individuais e sócioambientais da qualidade de vida percebida na carreira docente em educação física. Revista Brasileira de Educação Física e Esporte, 2007; 21(2):81-93.

9 O Grupo WHOQOL. A qualidade Organização Mundial da Saúde de avaliação de vida (WHOQOL): documento de posição da Organização Mundial da Saúde. Soc Sci Med. 1995; 41: 1403-1410.

10 Fernandes MH, Rocha VMD. Impact of the psychosocial aspects of work on the quality of life of teachers. Revista Brasileira de Psiquiatria, 2009;31(1): 15-20.

11 Kuroiwa DN, Marinelli JG, Rampani MS, Oliveira W, Nicodemo D. Desordens temporomandibulares e dor orofacial: estudo da qualidade de vida medida pelo Medical 18 Outcomes Study 36 - Item Short Form Health Survey. Rev Dor. São Paulo, 2011 abr-jun; 12(2): 93-8.
12 Koetz L, Rempel C, Périco E. Quality of life of professors of higher education community institutions in the state of Rio Grande do Sul, Brazil. Ciência \& Saúde Coletiva, 2013; 18(4): 1019-1028.

13 Araújo, TMD, Carvalho FM. Condições de trabalho docente e saúde na Bahia: estudos epidemiológicos. Educação \& Sociedade, 2009; 30(107): 427-449.

14 Contreras, AMS. Bruxismo: su comportamiento en un área de salud. Rev Ciencias Médicas. 2015; 19(1): 56-65.

15 Montero MPR. Associação da má oclusão e bruxismo com qualidade de vida de adolescentes. Bauru-2014.

16 Souza SD. Qualidade de vida de professores universitários em fase de mestrado. Dissertação de Mestrado, Faculdade de Engenharia de Produção, Universidade Federal de Santa Catarina. 2001.

17 Troman, G, \& Woods, P. Careersunder stress: Teacher adaptation sat a time of intensive reform. Journal of Educational Change. 2000; 1(3): 253-275.

18 Vanderas AP, Menenakou M, Kouimtzis TH, \&Papagiannoulis L. Urinary catecholamine levels and bruxism in children. Journal of oral rehabilitation. 1999; 26(2): 103-110.

19 Martins RJ, Garcia AR, Garbin CAS, Sundefeld MLM. Associação entre classe econômica e estresse na ocorrência da disfunção temporomandibular. Rev Bras Epidemiol. 2007;10(2): 215-22.

20 Leung, TW, Siu OL, Spector PE. Faculty stressors, job satisfaction, and psychological distress among university teachers in Hong Kong: The role of locus of control. International Journal of Stress Management. 2000; $7(2): 121-138$.

21 Carvalho AL, Cury AA, Garcia RC. Prevalence of bruxism and emotional stress and the association between them in Brazilian police officers. Braz Oral Res. 2008; 22(1):31-5. 